\title{
doispontos:
}

\section{Yvonne Rainer e os fins da dança: corpo, consciência e educação somática}

\author{
Ana Rita Nicoliello Lara Leite \\ Doutoranda em Filosofia pelo Programa de Pós-Graduação em Filosofia da FAFICH-UFMG, com pesquisa na linha \\ de estética e filosofia da arte. \\ anarita.nicoliello@gmail.com
}

Resumo: Neste artigo, articulo três sentidos distintos da expressão "Fins da Arte" - analítico-filosófico, estético e teleológico - para refletir acerca de um movimento importante no cenário da arte da dança, que transformou radicalmente o modo como nossa cultura ocidental compreende o corpo. Refiro-me à dança pós-moderna americana que se desenvolveu principalmente nas décadas de 60, 70 e 80, e tomo como paradigma o trabalho da coreógrafa, bailarina e cineasta Yvonne Rainer, denominado Trio A. Meu argumento é que, neste trabalho coreográfico, Yvonne Rainer coloca, com seu próprio corpo, a questão do "fim da dança" nos sentidos analítico-filosófico e estético, e como consequência promove uma reflexão sobre o "fim da dança" no sentido teleológico.

Palavras-Chaves: Fins da arte, dança, corpo, percepção, experimentação, experiência estética.

\section{Yvonne Rainer and the ends of dance: Body, consciousness and somatic education}

\begin{abstract}
On this paper, I articulate three different meanings of the expression "the ends of art" - analytic-philosophical, aesthetical and teleological - to reflect on an important movement in the dance art scene that has radically transformed how our Western culture comprehend the body. I refer to the American postmodern dance that was developed mainly in the 60s, 70s and 80s, taking as my paradigm the work of the choreographer, dancer and filmmaker Yvonne Rainer, called Trio A. I argue that in this piece Yvonne Rainer poses with her own body the question about "the ends of dance" in analythic-philosophical and aesthetical senses, and consequently invites us to reflect on "the end of dance" in a teleological sense.
\end{abstract}

Key-words: Ends of art, dance, body, perception, experimentation, aesthetic experience.

\section{Os vários fins da arte}

Num primeiro sentido filosófico-analítico, o fim da arte está relacionado ao declínio de uma tendência no pensamento filosófico de estabelecer critérios estáveis para diferenciação dos produtos artísticos de outros objetos e experiências do cotidiano. Diante da quebra de paradigmas tradicionais operada pelos movimentos vanguardistas do início do século XX e radicalizada pela arte contemporânea, tornaram-se bastante obscuras as fronteiras que delimitariam o escopo material e estético das obras de arte, o que dificultou largamente a tarefa do filósofo de definir critérios suficientes e necessários para discriminá-las e distingui-las de outros objetos ou experiências não-artísticas. Nesse sentido, a arte chegou ao fim, porque se não há critérios para definição do que ela é, não é possível distingui-la do que ela não é. 
Um segundo significado da expressão fim da arte diz respeito à transformação do próprio conteúdo estético das obras e, consequentemente, de seus modos de fruição. Trata-se do enfraquecimento da ideia de que a relação que estabelecemos com a Arte, com A maiúsculo, deve conduzir mulheres e homens a uma experiência prazerosa de contemplação da beleza, a um espetáculo extraordinário, que desloca e subleva o ser humano a um patamar transcendente. Nas palavras de Susan Foster (in DALY, 1992, p. 68), o afastamento da "teoria do gênio artístico como um comunicador extrassensível de uma experiência humana arquetípica bem como da relação do espectador ao evento baseada num acordo empático". A arte moderna e contemporânea, mais uma vez, põem em cheque essa visão da experiência estética, por adotarem procedimentos criativos que afastam a concepção de arte como contemplação, seja pela manipulação de materiais cotidianos nada nobres, seja pela incorporação de significados sociais, históricos e políticos que extrapolam a mera aparência sensível das obras, seja pela exploração do estrutural, do mínimo, do simples e do não-estético como forma de questionar o caráter artificioso da arte. O sentido de fim da arte, aqui, é estético.

Nos dois sentidos de fins da arte explicitados acima, o que está em questão não é propriamente a cessação da produção artística, mas um esfumaçamento dos limites da arte em sua relação com a vida, o que dificulta definições teóricas sobre sua essência ou sobre seu conteúdo estético. Contudo, isso não a torna uma atividade humana e social supérflua, e tampouco afasta sua potência fruitiva, porque mesmo que não possa ser definida, e mesmo que seu modo de fruição nem sempre seja o mesmo, a relação com obras de arte continua a produzir efeitos interessantes nas experiências humanas individuais e no mundo da cultura.

Esse paradoxo - fim da arte com produção artística - remente a um terceiro sentido de fim da arte, no qual a palavra fim na expressão tem o sentido de finalidade. Busca-se compreender, então, o que motiva homens e mulheres a produzir e a buscar o contato com a arte, do ponto de vista individual e coletivo, bem como quais são as consequências ou efeitos dessa atividade para o processo de produção subjetiva e de desenvolvimento social. Em outras palavras, por que e para que produzimos arte; qual é, afinal, a sua função e finalidade. Trata-se, portanto, de um sentido positivo e teleológico da expressão fim da arte.

\section{Dança: investigação do corpo}

A dança, uma espécie artística relativamente pouco tratada em filosofia ${ }^{1}$, tem uma especial particularidade em relação às outras formas de arte: a indiscernibilidade entre o artista (o bailarino), o material (o corpo do bailarino) e o produto estético final (o corpo do bailarino em movimento). Essa coincidência entre as categorias estéticas, somada ao fato de que na dança não há produção de objeto estético estável, mas a construção (coreografada ou improvisada) de acontecimentos ou eventos perfomativos corporais efêmeros - o que dificulta a compreensão filosófica do que, de fato, é uma determinada dança, enquanto uma obra de arte singular e distinta - intriga bastante alguns filósofos analíticos norte-americanos em suas discussões sobre o problema da identidade da arte do movimento ${ }^{2}$.

A coincidência das categorias estéticas levanta também questões sobre as fronteiras entre arte e vida (e consequentemente sobre os dois primeiros sentidos de fim da arte), já que o artista manipula, como material, a sua própria subjetividade, seu corpo próprio. $\mathrm{O}$ material da dança é o corpo vivo, senciente e sensível - o soma (SHUSTERMAN, 2012, p. 26) - o mesmo que o artista também habita em suas atividades cotidianas de perceber, conhecer e realizar tarefas. $\mathrm{O}$ artista da dança, para entrar na posse de seu material de trabalho, deve entrar na posse de si mesmo por meio do que Shusterman (2012) chama de consciência corporal e Gil (2002), falando especificamente da dança, denomina consciência do corpo. Trata-se do direcionamento da atenção consciente, por parte do dançarino, a determinadas partes de seu 
corpo, a suas relações e ao seu funcionamento global e integrado, de modo que qualquer movimento da consciência adquire a característica do próprio movimento corporal. Não se trata de uma visão externa e projetiva da consciência sobre o corpo, sobre sua forma ou sobre seu posicionamento no espaço, mas de uma ocupação plena do corpo pela atenção consciente.

Gil (2002, p. 99 e 105) fala da necessidade de produção de "uma osmose completa" entre consciência e corpo para que a dança aconteça e pontua que este movimento de imanência da consciência ao corpo é paradoxal, já que é justamente o que permite a abertura ao inconsciente do corpo. Mas inconsciente não se refere a nenhum sentido psicanalítico freudiano, e nem implica que o movimento da dança é uma atividade reflexa desprovida de consciência. "Simplesmente, já não se trata aqui da consciência entrópica que isola e paralisa o seu objeto a fim de (pensa ela) melhor lhe apreender o sentido" (GIL, 2002, p. 119).

Trata-se de uma diferença de modo de operação e engajamento da consciência na dança: não um movimento intencional em direção a um objeto em "carne e osso" (o corpo), mas um movimento "para trás", direcionado a um mundo de micropercepções que se operam na própria dimensão corporal ${ }^{3}$ e que abrem o corpo ao contato ou contágio com as forças do mundo. A consciência do corpo, oposta à consciência de si reflexiva, é obscura e confusa, porque não é pura, está impregnada de corpo, o lugar dos afetos, das forças e das pequenas percepções.

Essa revolução "para trás" da consciência em direção ao corpo, libera uma espécie de espaço interior do corpo $^{4}$ dirigido ao exterior (o movimento que se projeta para fora) no qual circulam livremente intensidades, forças, energia. Dançar é colocar essa energia para circular, uma atividade na qual a tensão necessária para que um movimento seja realizado é reaproveitada como impulso para o movimento seguinte, que se delineará sem redirecionamentos cortantes do fluxo ${ }^{5}$. Não se representa imagem de corpo na consciência, esta é tomada pelo corpo enquanto campo de forças, permitindo com que a dança se desenvolva no espaço, de dentro para fora. Para Gil, o dançarino perfura o espaço físico com o espaço do corpo, criando o próprio espaço a partir de uma força, energia, potência que emana de seu interior. A pele já não delimita mais o que é interno e externo, funcionando como uma superfície de trânsito de intensidades.

\section{Yvonne Rainer, recusa e fim}

Essa concepção de dança defendida por Gil deve muito às experimentações de alguns artistas americanos a partir da década de 60, que sentiam que seus corpos e suas capacidades criativas eram tolhidas pelos cânones que vigoravam no mundo da dança até então. Rebelando-se contra os ideais estéticos tanto da dança moderna que lhes antecedeu quanto da danse d'ecole do balé clássico, esses artistas estavam interessados em investigar o que, de fato, constituía uma dança, quais eram seus elementos essenciais (se é que existem) e como o seu medium - o corpo - pode ser produtiva e livremente engajado nesta atividade.

A historiadora e crítica de dança Sally Banes denomina de dança pós-moderna esse movimento que se desenvolveu nas décadas de 60, 70 e 80 nos Estados Unidos, mas salienta que o uso da expressão "pós-moderno" no universo da dança se distingue das comuns acepções do termo em outros contextos. Aqui, a expressão tem uma conotação histórica e descritiva, embora pouco precisa: refere-se a dança que se desenvolveu posteriormente à dança moderna (cujas principais representantes americanas eram Martha Graham e Doris Humphrey) e que apresentava princípios estéticos opostos tanto a esta quanto ao balé clássico (BANES, 1987, pp. xiii-xv; e BANES, in DALY, 1992, p. 59). Esses princípios estéticos não podem ser unificados em um movimento estilístico único, pois os métodos e pragmáticas de compreensão da dança variaram no decorrer das três décadas ${ }^{6}$. Contudo, Ann Daly (1992, p. 49), outra estudiosa da dança, 
salienta que parece haver uma ideologia comum aos dançarinos pós-modernos: "algo relacionado à visão contracultural do corpo como um processo generativo - como uma fonte de conhecimento social - e como um quadro público para inscrever e disseminar conhecimento"7.

De todo modo, o marco inicial da dança pós-moderna americana é geralmente identificado com o primeiro concerto do coletivo de artistas Judson Church Dance Theater, em julho de 1962 numa igreja de Greenwich Village em Nova Iorque, que incluía trabalhos de Yvonne Rainer, Steve Paxton, Trisha Brown, Lucinda Childs, David Gordon, Alex e Deborah Hay, Robert Morris e Robert Rauschenberg.

Esses artistas estavam dispostos a ir até o fim no que se refere à pergunta "o que é uma dança?", a partir da experimentação radical do próprio corpo como seu tema principal. Afastavam-se dos ideais clássicos, porque o corpo que investigavam não era aquele que podia aprender um conjunto de passos para executá-los da maneira mais correta e virtuosa possível, tampouco o corpo que exprimia estados emocionais interiores, como no ideário da dança moderna. O corpo que buscavam não era aquele que representava situações, narrava histórias ou expressava sentimentos. Todos esses corpos foram fabricados no decorrer da história da dança como corpos ideais, com o auxílio de espetaculosos cenários, figurinos e fundos musicais, camuflando o corpo que uma dança, afinal, apresenta: um corpo real, humano, cotidiano, físico; um corpo que se movimenta, que perde e ganha equilíbrio, que pesa; um corpo que percebe, age e pensa; um corpo orgânico inserido num contexto cultural e social, e, portanto, marcado por ele.

Era necessário um movimento de desconstrução: tirar de vista tudo o que não era essencial à dança, todo o artifício - como cenário, figurino, música, discursos sobre o corpo e sobre a dança - para que fosse possível, enfim, visualizá-la. O movimento do corpo cotidiano, do corpo puro, exigia uma descodificação, isto é, um abandono dos códigos da dança clássica e moderna para que fosse possível emergir o gesto não-teatral, no qual o corpo não é manipulado ou tensionado mais do que o necessário para fazer de um movimento cotidiano um movimento dançado. Também exigia uma despersonalização anti-narcísica do performer-dançarino: sua performance deveria ser neutra, sua subjetividade transparente e seus movimentos objetivos, pois é seu corpo o que deve ser visto, não qualquer estado interior que mereça ser expressado, nem uma virtuose técnica que mereça ser demonstrada.

A estética da dança pós-moderna é uma estética da recusa - por isso a famosa frase de Steve Reich: "por um longo tempo durante a década de 60 as pessoas iam ao concerto de dança onde ninguém dançava, seguido da festa onde todos dançavam" (in COPELAND, p. 66) - e foi Yvonne Rainer seu paradigma (BANES, 1987, p. 44). Em 1965, ela formula o manifesto tão citado que dita os princípios da nova dança pós-moderna:

\footnotetext{
não ao espetáculo, não ao virtuosismo, não às transformações e à magia e ao uso de truques, não ao 'glamour' e à transcendência da imagem da star, não ao heroísmo, não ao anti-heroísmo, não às imaginárias de pechisbeque, não ao comprometimento do bailarino ou do espectador, não ao estilo, não às maneiras afetadas, não à sedução do espectador graças aos estratagemas do bailarino, não à excentricidade, não ao fato de alguém se mover ou se fazer mover (in RAINER, 1961-1973, p. 51, apud BANES, 1987, p. 43 e GIL, 2002, p. 143).
}

Em 1966, apresenta pela primeira vez Trio A, chamada, na época de The Mind is a Muscle, Part 1, uma frase coreográfica de quatro minutos e meio que põe em prática todas as recusas apontadas por Rainer no manifesto um ano antes ${ }^{9}$. Nesta coreografia, Rainer se movimenta de um modo despretensioso, funcional, direto e natural, trabalhando principalmente com a distribuição homogênea de energia, tanto no sentido de doar a cada movimento apenas quantidade suficiente e necessária de força para realizá-lo sem qualquer teatralidade, quanto no sentido de executá-los continuamente, sem pausas ou sobressaltos, numa relação equitativa das partes, evitando a sensação de desenvolvimento, clímax e contrastes. 
Esse trabalho de equalizar a energia está relacionado à sua tentativa de desestilizar os movimentos e desartificializar a dança: o movimento dançado deve ter a mesma energia que o movimento real e o desenrolar da dança deve ocorrer na mesma transitoriedade contínua dos próprios processos vitais. É por isso que Banes entende que o estilo de movimento de Rainer em Trio A é factual: "nem fatores de peso, nem de tempo e espaço são notadamente estilizados ou enfatizados. $O$ único fator que é obviamente alterado e manipulado é o do fluxo de movimento" (BANES, 1987, p. 47), no sentido de que, apesar de a dançarina realizar uma série de movimentos disjuntivos que não se repetem - isolando movimentações de cabeça, de tronco e de membros para que se tornem evidentes - a homogeneidade energética na execução da série dá a sensação de um fluxo contínuo de movimento repetitivo.

De todo modo, a ordenação dessa trança intrincada de movimentos não é externa, ela advém de como o peso real do corpo precisa ser organizado no tempo real de execução de cada um dos movimentos, numa temporalidade de constante transições.

Yvonne brinca com o aparecer e o desaparecer do esforço necessário para empreender cada movimento: aparentemente, a dança é sem esforço, mas manter essa homogeneidade energética exige da dançarina, na verdade, um grande esforço, que se relaciona ao movimento da consciência do corpo de que nos fala Gil. Mas paradoxalmente, ela deixa visível esse esforço real necessário para executar os movimentos, ela não usa artifícios para que seu corpo pareça mais leve do que realmente é. Ela torna desnudo o processo criativo da dança, e nesse jogo do aparecer e do desaparecer do esforço, faz visível o que uma dança é, de fato: o próprio movimento no tempo de um corpo $\mathrm{nu}^{10}$.

Mas afinal, seria esse movimento ainda dança? A última recusa de Rainer no manifesto é: "não ao fato de alguém se mover ou fazer mover" o que, em outros termos, é a recusa da própria dança. É assim que os dois sentidos de fim da arte - o filosófico-analítico e o estético - aparecem com radicalidade na obra de Rainer, a partir de seu ato duchampiano de, recusando tudo o que não é essencial à arte da dança, encontrar um objeto comum, não-artístico, um ready-made. Nas palavras de Gil (2002, p. 144), "alcançar enfim a pureza essencial do movimento é também anulá-lo totalmente".

\section{0 que Trio $A$ ainda pode nos ensinar sobre o corpo?}

Embora a tarefa de Yvonne Rainer e de seus companheiros pós-modernos tenha se mostrado, afinal, impossível - o essencial da dança escapa para algo que está na própria vida - a crítica assimilada à história da dança por meio de suas experimentações radicais provocou uma transformação no que se entendeu, posteriormente, por dança, enquanto uma forma de arte.

A dança pós-moderna não foi, portanto, apenas um novo estilo que surgiu na década de 60 - um estilo minimal e austero, que logo perdeu força para um estilo mais enérgico, musical e divertido na década de 80 - mas fez emergir uma nova definição de dança (BANES, 1987, p. 49), que certamente inclui aspectos institucionais, epistemológicos e políticos para além dos estéticos ${ }^{11}$.

Não que Trio A seja um paradigma estético que deva ser seguido por coreógrafos e bailarinos, mas é inegavelmente um marco crítico importante no universo da dança por colocar questões sobre liberdade do corpo em contraste a sistemas autoritários de organização corporal. Trio $A$ funciona como uma "espécie de catálogo de possibilidades de movimento e combinações para o corpo humano" (BANES, 1987, p. 47), porque libera as forças produtivas do corpo, sem apelo a sedimentações idealizadas externas. Por isso é que Gil diz que Trio A "põe a nu as condições de possibilidade de qualquer obra dançada" (GIL, 2002, p. 158), 
porque nos faz visualizar o próprio movimento das forças, que torna possível a emergência de um outro corpo que dança, um corpo virtual, estranho (mesmo que ordinário) e ainda desconhecido.

Não é, portanto, apenas sobre dança que falavam Yvonne Rainer e seus colegas pós-modernos. Falavam também sobre política e epistemologia do corpo, sobre abrir o corpo às pequenas percepções, torná-lo sensível e agir sinceramente, sem recurso a artifícios que afastam a própria corporeidade. Impregnar-se de corpo para descobrir novas possibilidades perceptivas, relacionais e de pensamento. Mas paradoxalmente, é pela dança que fazem isso, porque, nas palavras de Gil (2002, pp. 55-56) "a dança opera uma espécie de experimentação pura dessa capacidade do corpo de se agenciar, criando um laboratório onde todos os agenciamentos possíveis são testados". Seria esse, então, o "fim da dança", num sentido teleológico?

\section{Teleologia da dança e educação somática}

Embora a discussão sobre uma possível teleologia da obra de arte corra o risco de se impregnar de valorações morais, se entendermos a finalidade não como uma imposição anterior, racional e moralizante sobre o conteúdo estético da dança, mas como um efeito ou consequência que pode surgir do próprio processo de experimentação com o corpo, podemos esboçar uma resposta afirmativa a essa pergunta. Aqui, a teleologia da obra de arte é entendida num sentido dado pelo filósofo John Dewey, quando tratou da experiência estética, em seu livro Arte como Experiência (1934).

Para o filósofo pragmatista, a experiência estética é um modo especial de relação que estabelecemos com e no mundo, na qual potencializamos nossas capacidades perceptuais e simbólicas, em razão de uma reorganização de qualidades sensíveis compartilhadas. É, portanto, uma espécie de relação em que uma criatura como o ser humano, que é tanto sensível como racional, encontra-se temporariamente em equilíbrio, já que ambos seus aspectos são estimulados. A experiência estética, para Dewey, é a prova de que não somos seres duais: corpo e mente estão integrados numa atividade perceptiva rica, que nos desloca dos lugares comuns da percepção empobrecida, do mero reconhecimento cotidiano, e nos integra numa totalidade cujo sentido é intuído emocionalmente, para além do domínio da linguagem ${ }^{12}$.

A arte, incluindo a dança, é uma atividade humana que visa à produção desse tipo de experiência. Não que seja ou deva ser sempre bem-sucedida em concretizar essa produção. A teleologia da obra de arte, nesse sentido, não é normativa. Mas a arte é uma atividade que tem potencial para funcionar como um catalisador de experiências estéticas. É nesse sentido, de potencialidade de efeitos, que o caráter teleológico é aqui entendido. Isso porque, no processo relacional entre o artista e o fruidor mediado pelo objeto ou acontecimento estético, experiência sensível e simbólica podem ser produzidas de um modo intensificado e não-instrumental. É para isso, então, que a arte pode servir: para não servir a nada, exceto enriquecer, sensível e simbolicamente, a experiência humana.

A arte que produz experiência estética desafia as maneiras usuais de um ser humano perceber o mundo, porque exige, tanto do artista como do fruidor, um modo intensivo de percepção criativa ${ }^{13}$, um modo especial de se colocar no mundo, que implica curiosidade, abertura à multiplicidade sensível e disponibilidade para perceber o não-usual, incorporá-lo e responder a ele. E se a dança é a arte corporal por excelência, talvez ela possa funcionar como uma verdadeira linha de fuga para uma operação de ressensibilização do corpo e potencialização de suas capacidades perceptuais ${ }^{14}$.

Arrisco dizer, para finalizar, que o tipo de experiência estética que a dança pode produzir está relacionado, então, a um certo tipo de educação somática: exercício e treinamento de micropercepções, novos engajamentos 
corporais e maior liberdade de colocar o corpo no mundo. Significa dizer que o modo como os artistas têm usado o corpo num paradigma investigatório, exploratório e libertário nos permite, se estivermos suficientemente abertos e disponíveis, ressignificá-lo e expandir nossas próprias experiências corporais.

Dançar é, afinal, sempre se perguntar: o que pode um corpo?É uma espécie de investigação prática acerca do que um corpo pode fazer, para além das tarefas habituais determinadas pela consciência, para além das estratificações sociais que enquadram os gestos, para além das significações que o impregnam de valores. E ver uma dança é sempre fazer a mesma pergunta, sobretudo porque o corpo que dança é humano - mas pode devir outro.

\section{NOTAS}

1. Segundo Sparshott (1983), a dança não era originariamente uma categoria das belas artes no sistema artístico do século XVIII, que culminou com a estética de Hegel, o que influenciou toda uma geração de filósofos a ignorar a dança em suas análises estéticas da arte. Cf. Sparshott, Francis. The Missing Art of Dance, in Dance Chronicle, 1983, vol.6, n. 2, pp. 164-183.

2. Sobre esse debate, $c f$. Bresnahan, Aili. The Philosophy of Dance. In The Stanford Encyclopedia of Philosophy (Winter 2016 Edition), Edward N. Zalta (ed.), URL = <https://plato.stanford.edu/archives/win2016/entries/dance/>.

3. Neste sentido, Gil (2002, p. 133) critica a concepção fenomenológica da consciência e distingue a consciência do corpo da simples consciência de um estado interno do corpo, como uma dor ou um sentimento. No segundo caso, há intencionalidade direcionada a objeto - um aspecto do próprio corpo - no outro, não há intencionalidade, pois o corpo não é simplesmente o objeto ao qual a intencionalidade se dirige, mas é o locus da consciência, que o ocupa plenamente.

4. Gil denomina esse espaço de zona ou espaço interior virtual. Cf. GIL, 2002, pp. 119-137.

5. Mesmo no balé clássico, para Gil, o bailarino não trabalha com uma simples imagem visual de seu próprio corpo e do que ele deve fazer para dançar. Ele faz, ao contrário, "corresponder certa posição dos membros a certa tensão cinestésica, construindo assim um mapa interior dos movimentos que lhe permitirá evoluir de modo preciso sem ter já de recorrer a uma imagem exterior do seu corpo" (GIL, 2002, p. 47). Esse mapa energético é o que justamente permite um livre fluxo de intensidades, porque ele "é construído sobre a energia e não sobre movimentos concretos" (GIL, 2002, p. 56).

6. Para Banes (in DALY, 1992, p. 60), a dança pós-moderna é, ao mesmo tempo, principalmente nas décadas de 60 e 70, modernista (no sentido de se especializar em sua essência enquanto distinta de outras artes - ideia de pureza) e anti-modernista, principalmente na década de 80 (no sentido de ser pautada pelo ecletismo, pela mistura de linguagens artísticas, pela imbricação entre a cultura de massa e a arte erudita, pelo pastiche, etc). Para outras visões sobre a dança pós-moderna e o que restou dela, cf. DALY, Ann (ed.). What has become of postmodern dance?, in The Drama Review, vol. 36, n. 1 (Spring 1992), pp. 48-69.

7. Livre tradução do original em inglês.

8. Tradução livre do original em inglês.

9. RAINER, Yvonne. Trio A. Disponível em https://www.youtube.com/watch?v=Em_-A44HNzc, acessado em março de 2017.

10. "O extraordinário feito de Trio A foi tornar visível esta coreografia do tempo implicada em toda a dança" (GIL, 2002, p. 153) 
11. Segundo Gil (2002, p. 141), trata-se do entendimento da dança enquanto um dispositivo, no sentido foucaultiano.

12. A experiência estética é caracterizada como uma experiência satisfatória, não num nível superficial de agradabilidade e prazer, mas num nível profundo de integralidade relacional; o que a caracteriza e a distingue de outras experiências humanas é o sentimento de satisfação presente quando finalizamos um intenso processo de trabalho - perceptivo, emocional e intelectual - e somos capazes de organizá-lo, retroativamente, em uma experiência integrada e com sentido. Enfim, a experiência estética é aquela que possui forma. Para Dewey, essa experiência enformada não é produzida exclusivamente no contato com as belas artes, isto é, com os objetos estéticos referendados pela cultura a partir de instituições especializadas, como museus e galerias. $\mathrm{O}$ potencial da forma está presente em qualquer experiência cotidiana que não seja conduzida de modo mecânico, mas na arte ele é intensificado. Cf. DEWEY, 2012, pp. 109-141.

13. Para Dewey, a percepção é sempre criativa, porque envolve dois níveis da natureza humana, que não se opõem num dualismo cartesiano, mas se imbricam naturalmente: o físico - o corpo, a dimensão dos significados incorporados - e o simbólico - a mente, a dimensão dos significados linguísticos explícitos e proposicionais. A percepção, para Dewey, portanto é ação, e não meramente uma ação de recognição. Não se trata de uma re-presentação do mundo na mente, mas de uma re-organização inteligente de hábitos incorporados a novas situações que se apresentam. A não dualidade entre corpo e mente é resolvida no entendimento do self como um eu transacional (SHUSTERMAN, 2012, p. 331), um sujeito não-atômico num constante processo de produção de si mesmo a partir das interações que estabelece com o mundo.

14. Sobre a importância do cultivo do corpo como mecanismo de aumento de potência experiencial, cf. SHUSTERMAN, 2012, p. 323: "Ao permitir que sintamos mais de nosso universo com maior precisão, percepção e apreciação, essa visão do cultivo somaestético promete o mais rico e profundo paladar de realizações experienciais (...) Pode-se assim chegar a intensidades encantadoras de experiência na vida cotidiana, sem recurso a medidas violentas de intensificação sensorial que ameaçam a nós e a outrem”. Essa associação da qualidade da percepção ao engajamento corporal é também sustentada por vários pensadores de diferentes correntes filosóficas. A título de exemplo, cito os pragmatistas John Dewey ( $c f$. DEWEY, John. Human Nature and Conduct - An introduction to social psichology. New York: Henry Holt and company, 1922) e Richard Shusterman (cf. SHUSTERMAN, Richard. Consciência Corporal. São Paulo: Realizações Editora, 2012), o fenomenólogo Maurice Merleau-Ponty ( $c f$. MERLEAU-PONTY, Maurice. Fenomenologia da Percepção. 2a ed. São Paulo: Martins Fontes, 1999) e o filósofo analítico Alva Nöe (cf. NOË, Alva. Action in Perception. Massachusetts: MIT Press, 2004).

\section{REFERÊNCIAS}

BANES, Sally. Terpsichore in sneakers. Post-modern dance. Middletown: Wesleyan University press, 1987.

BOURCIER, Paul. História da dança no ocidente. São Paulo: Martins Fontes, 2001

BRESNAHAN, Aili. The Philosophy of Dance. In The Stanford Encyclopedia of Philosophy (Winter 2016 Edition), Edward N. Zalta (ed.), URL $=<$ https://plato.stanford.edu/archives/win2016/entries/dance/ >.

CAUQUELIN, Anne. Arte Contemporânea. Uma Introdução. São Paulo: Martins Fontes, 2005.

COPELAND, Roger. Postmodern Dance/ Postmodern Architecture/ Postmodernism. Performing Arts Journal 7, n. I (PAJI9), 1983, pp. 27-43.

DALY, Ann (ed.). What has become of postmodern dance?, in The Drama Review, vol. 36, n. 1 (Spring 1992), pp. 48-69. 
DEWEY, John. Human Nature and Conduct - An introduction to social psichology. New York: Henry Holt and company, 1922.

. Experience and Nature. London: George Allen \& Unwin, 1929.

. Art as Experience. New York: G. P. Putnam’s sons, 1934.

. Arte como Experiência. São Paulo: Martins Fontes, 2012.

GARAUDY, Roger. Dançar a vida. Rio de Janeiro: Nova Fronteira, 1980.

GIL, José. Movimento Total. O corpo e a dança. São Paulo: Iluminuras, 2002.

GOMBRICH, E. H. The story of art. 16ª ed. London: Phaidon, 1995.

MERLEAU-PONTY, Maurice. Fenomenologia da Percepção. 2a ed. São Paulo: Martins Fontes, 1999

NOË, Alva. Action in Perception. Massachusetts: MIT Press, 2004.

RAINER, Yvonne. Trio A. Disponível em https://www.youtube.com/watch?v=Em_-A44HNzc, acessado em março de 2017.

SHUSTERMAN, Richard. Why Dewey Now?, in Journal of Aesthetic Education, Vol. 23, No. 3 (Autumn, 1989), pp. 60-67. Disponível em http://www.jstor.org/stable/3332763, acessado em 14/12/2012.

. Consciência Corporal. São Paulo: Realizações Editora, 2012.

SPARSHOTT, Francis. The Missing Art of Dance, in Dance Chronicle, 1983, vol.6, n. 2, pp. 164-183. 